\title{
Framing Genomics, Public Health Research and Policy: Points to Consider
}

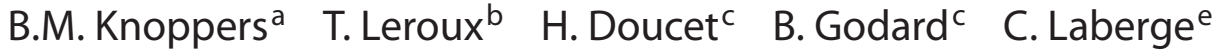 \\ M. Stanton-Jean ${ }^{b}$ S. Fortin ${ }^{b} \quad$ J. Cousineau ${ }^{b} \quad$ C. Monardes ${ }^{b} \quad$ N. Girard ${ }^{b}$ \\ L. Levesque ${ }^{c} \quad$ C. Durand ${ }^{c} \quad$ Y. Farmer ${ }^{d} \quad$ M. Dion-Labrie ${ }^{d} \quad$ M.-E. Bouthillier ${ }^{d}$ \\ D. Avard ${ }^{a}$
}

${ }^{a}$ Centre of Genomics and Policy, Department of Human Genetics, McGill University, ${ }^{b}$ Centre de Recherche en Droit Public, ' Programmes de Bioéthique and d Groupe de Recherche en Éthique Biomédicale, Université de Montreal, Montreal, Qué., and 'Médecine génétique, Université Laval, Ste-Foy, Qué., Canada

\section{Key Words}

Access $\cdot$ Genomics research $\cdot$ Governance $\cdot$ Privacy $\cdot$ Public health - Public participation - Stakeholder perceptions •

State powers

\begin{abstract}
Genetic information can be used to target interventions that improve health and prevent disease. Indeed, the results of population genomics research could be useful for public health and national pandemic plans. Yet, firm scientific evidence originating from such research and the indicators of the role of health determinants, gene-gene and gene-environment interaction remain to be assessed and validated before being integrated into pandemic plans or public health programmes. It is not clear what is the role of the State in research on the elucidation of the determinants of gene-gene and gene-environment interactions and how, when, and if such data can be accessed and used for such planning. Over a period of 3 years, we sought to address these questions by gathering data and literature relevant to research in public health genomics, preparing issues papers and, finally, consulting with stakeholders on a provisional 'points to consider' document at various times. Examining in turn the issues of privacy, State powers, stakeholder perceptions, and public participation, we propose in this article, for each of these
\end{abstract}

themes, a series of recommendations aiming to provide guidance on the role of the State in the use of genomic information for public health research, prevention and planning.

Copyright $\odot 2010$ S. Karger AG, Basel

\begin{abstract}
$[\mathrm{M}]$ odern genetics - enhanced by genomics, proteomics, and bioinformatics - has the potential to contribute to scientifically sound strategy for improving health and preventing disease, the overarching mission of public health [...] [but the] goal of protecting individual privacy and the confidentiality of medical information may block the large population studies required to answer questions from patients, families, communities, and policymakers about improving health care and public health protection. [1]
\end{abstract}

\section{Introduction}

For almost 5 decades, it has been maintained that genetic information could be used to help improve health and prevent disease $[2,3]$. The Human Genome Project aimed to provide the tools for the translation of genomic knowledge to clinical diagnosis at every level of the health care system [4]. Today, large population cohort studies involving biobanks contribute to the assessment of the role of genes and the environment in common diseases [5]. In

\section{KARGER \\ Fax +4161306 1234 \\ E-Mail karger@karger.ch}

www.karger.com
(C) 2010 S. Karger AG, Basel

$1662-4246 / 10 / 0134-0224 \$ 26.00 / 0$

Accessible online at:

www.karger.com/phg
Bartha Maria Knoppers, PhD

Centre of Genomics and Policy, Faculty of Medicine, Department of Human Genetics McGill University, 740 Dr. Penfield Avenue, Room 5214

Montreal, Que, H3A 1A4 (Canada)

Tel. +1 514398 8866, Fax +1 514398 8954, E-Mail bartha.knoppers@ mcgill.ca 
fact, population-based research aims to 'discover population-based methods that protect the health of the community. In general, population-based research is conducted to identify population-based risk factors and interventions to prevent the onset of, interrupt the progression of, or ameliorate population-based disease' [6].

Indeed, a better understanding of what lies between the genes that make up the genome, the role of the environment on gene expression and the role of the interaction between genes will help us to know why some individuals remain healthy while others are more susceptible to genetic diseases. This understanding will also benefit the public health sector where the prevention and expression of communicable and infectious diseases, for example, is related in part to understanding genetic susceptibility (e.g. SARS, TB, H1N1, etc.) [7]. To date, biobanking and public health surveillance have been looked at independently from each other [8]. In fact, the assimilation of genomics into the public health response to conditions like 'cancer clusters, outbreaks of infectious diseases [...] [and] effects of toxic exposure, or adverse events following vaccination' [9] remains a great challenge. But current consent and privacy mechanisms, when applied to population genomic studies and accompanying databases, may limit their use for public health research [10-12].

To achieve the integration of research in population genomics with public health, governments and researchers will need to access genomic databases, or even to create databases that may be of interest for public health research and practice. The problem is that existing databases may have been created for other purposes. Indeed, they may be general and anonymised, or coded for research purposes, or disease-specific, or may be based only on a particular population (e.g. newborn screening programmes). This means that the individuals, families and communities or populations involved may not have expressly consented to studies on the relationship between the human genome and susceptibility to communicable or infectious diseases for example [13]. Likewise, new databases created for the surveillance of genetic susceptibility will also generate some controversy.

Canada, with its universal health care system and its strength in genomic research, is well placed to address the issue of the access to or creation of genomic databases by public health researchers for the understanding and control of infectious diseases [14]. However, many questions remain: How do we balance the potential interests of the 'at-risk' population in the presence of infectious or communicable diseases against the confidentiality of individual or community genetic information and the se- curity of such databases? Can these databases be accessed by the State in the public interest or for the public good? In answering these questions, one should remember that publicly funded research is a public good and ensuring that research data is easily accessible is 'primarily a matter of sound stewardship of public resources' $[15,16]$.

Currently in Canada, in the absence of emergencies, State powers to access genomic databases for research purposes are not clearly established. Indeed, mediumand long-term objectives should be adopted in relation to the possible future use of research results for public health interventions such as public health promotion, prevention and planning. To that end, the 'strategic approach', a version of the precautionary principle [17], based on the notion that obtaining scientific certainties, cannot always be done in a timely manner so as to allow for the guidance of collective choices.

Given the sensitivity of many ethical questions related to secondary access to databases for the study of genetic susceptibility, such as surveillance plans, public health preparedness and responses to pandemics, stakeholder and public considerations are crucial. Furthermore, a well-designed ethical framework is needed to guide the policy-making process. The results of population genomics research could be useful for public health and national pandemic plans. Yet, solid scientific evidence emanating from such research and the indicators of the role of health determinants remain to be evaluated and justified before being incorporated into pandemic plans or public health programmes.

Examining in turn the issues of privacy, State powers, stakeholder perceptions, and public participation, we will propose for each of these themes a series of recommendations aiming to provide guidance on the role of the State in the use of genomic information for public health research, prevention and planning. The aim was to see if citizens and governments would be comfortable with genomic information being integrated and used in pandemic planning in the absence of emergency situations. This paper describes the methods used and discusses the grounds for concerns. It also suggests several recommendations regarding the 4 domains of State powers, privacy, stakeholder and public perceptions.

\section{Methodology}

A key objective of the 'Genomics and Public Health: Building Public "Goods"?' project was to translate our research into a document that enables policy-makers and others to consider the implications of integrating public health genomics within public 
health research. To achieve this we undertook literature reviews in the 4 domains and initiated a consultative process. The development of a 'points to consider' (PTC) document was undertaken over a period of 3 years between 2006 and 2009 and consisted of the following stages: gathering information or literature review relevant to research in public health genomics, preparing issues papers, and consulting with stakeholders on provisional PTC statements at various times.

\section{Literature Review and Data Gathering}

Laying the groundwork for the consultative process began with a review of the scientific, ethical and legal literature. This began with an international conference, the 4th International DNA Sampling Conference: 'Genomics and Public Health' addressing issues of biobanking, population cohorts, newborn screening, and the role of citizens, later published as a book [18]. Following the conference, 4 major studies looked at the determination and characteristics of privacy issues, State powers, stakeholder perceptions, and public participation.

In the privacy and access to personal data section, a 2-step analytical approach was adopted: (a) a review of the legislation of Quebec, Ontario and Alberta as well as of guidelines and legal doctrine pertaining to privacy and medical confidentiality, and (b) a study of Canadian legislation with international approaches to privacy and public health research in other multi-jurisdictional countries, specifically Germany, Australia, the United States, and the United Kingdom.

Under State powers, a 4-step analytic approach of the domain of public health included: (a) a comparative analysis of public health legislation in Canada and internationally (e.g. United Kingdom, Switzerland, New Zealand); (b) a study of State powers in Quebec to collect data in the context of surveillance, vigilance, and emergency situations; (c) a review of policy documents on State Powers such as the pandemic plans of the WHO, Canada and Quebec; and (d) the possible application of the precautionary principle was considered as a possible avenue to justify State access to and use of genomic databases for research purposes or in the case of a pandemic.

As indicated in the introduction, it was considered important to obtain the perspectives of stakeholders interested in public health genomics. A non-probabilistic, purposive sample of different stakeholders in Quebec concerned with public health genomics issues were interviewed, including policy-makers (7), epidemiologists and virologists (7), genomics researchers (9), and ethics and law specialists (10). The sampling continued until data saturation occurred (i.e. the point when new information produces little or no change). Respondents were contacted by telephone and internet. With their informed consent, interviews were tape-recorded and transcribed for thematic analysis. Ethics approval was obtained from the University of Montreal.

Finally, the public dialogue on public health issues consisted of hosting a citizen workshop using a hypothetical scenario on infectious disease to examine the implications and acceptability of public health genomics. The citizen workshop was held in April 2008 [19] to discuss the possible role of citizens in the development of pandemic influenza plans. This workshop brought together 15 citizens to discuss a range of topics: the decision-making process, communication, use and organisation of health and social services, and the role of genomic data in a pandemic influenza. Table 1 summarises the approach employed.
Table 1. Citizen Workshop, April 11-13, 2008; objective: to explore the role and contribution of citizens in planning and responding to an influenza pandemic using genomic information

An advisory committee was formed to provide direction for the Workshop.

The advisory committee consisted of representatives in planning, public participation, genomics and the elaboration of pandemic plans.

Recruitment was through the media.

A press release was sent to various Montreal newspapers.

Written information on pandemics and genomics was circulated.

Basic information material was handed out during the workshop.

A moderator, with extensive experience in group animation, hosted the Citizen Workshop.

The Citizen Workshop involved 15 citizens over three days.

- It started with the presentation of the project followed by a general tutorial on pandemics.

- The citizens were able to discuss four themes related to the subject.

- Every session of the workshop, comprising half a day by theme, started with a presentation by an expert giving information to participants.

- The presentations lasted 30 to 45 minutes and were followed by a short question period.

- Finally, a discussion between citizens was undertaken.

The tape-recorded information was analyzed according to four key themes:

- decision process

- communication

- state powers and citizen's liberties

- organization of care and services (using genomic information)

A follow-up meeting to validate findings was hosted on June 7, 2008.

\section{Issues Papers}

Several issues papers were produced to report the key findings of our initial review of the literature and were submitted as separate papers to scientific journals. These papers were developed to report key themes and issues emerging from the literature and policy review on: State powers [20], privacy [21], stakeholder perceptions [22], and the role of the public in international pandemic plans [23-26]. These documents helped formulate the provisional PTC along with the recommendations. The team met quarterly to discuss the analysis and agreed about the common themes and the eventual recommendations.

\section{Consultative Process}

In addition to the document review and data gathering, a consultative process was initiated to obtain a broad representation of perspectives. Workshops were hosted in partnership with (a) students, (b) stakeholders, (c) collaborators, and (d) policy-makers. The main purpose of these workshops, hosted periodically during the course of the project, was to supplement our data gathering phase and seek input on the potential implications of our PTC. 


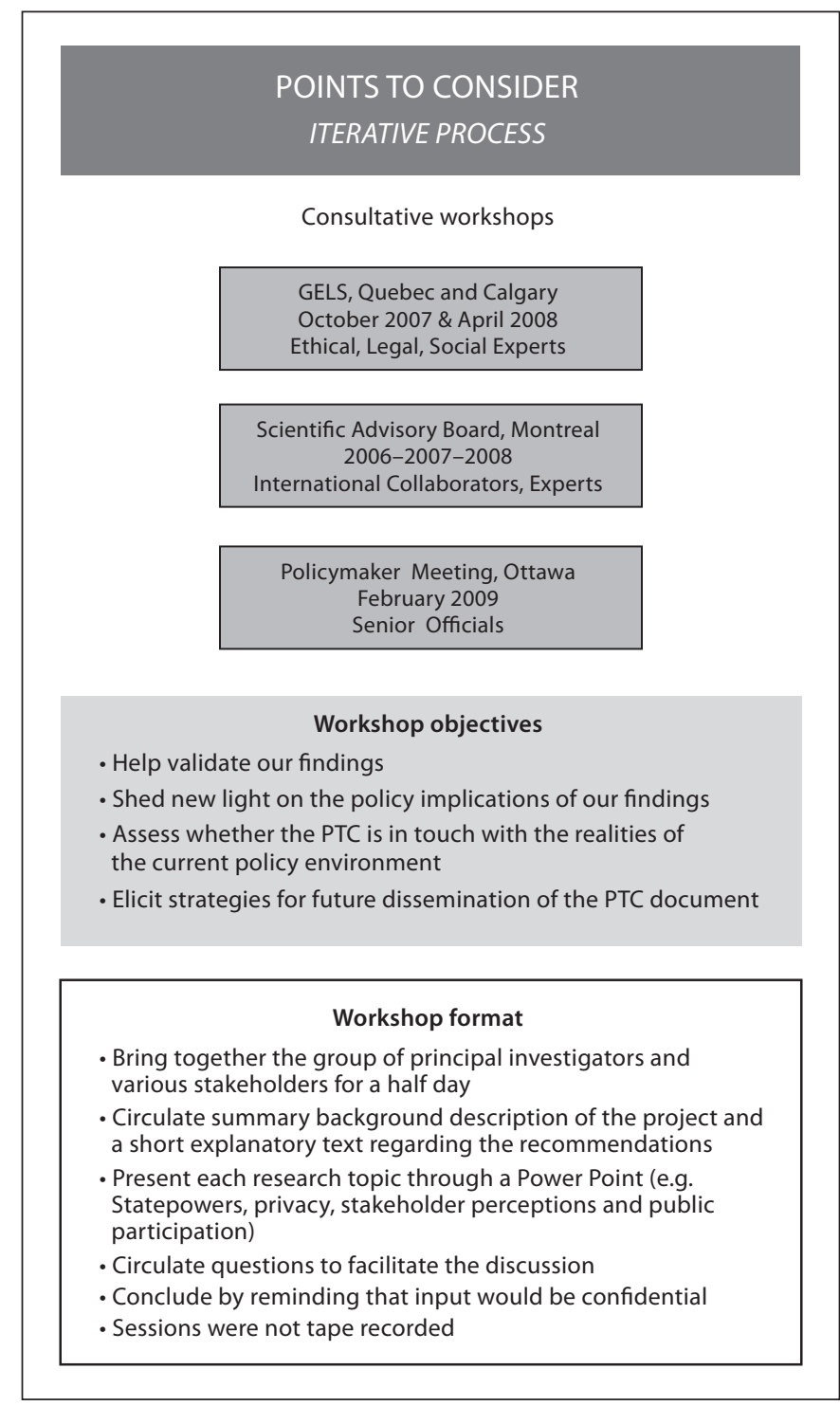

Fig. 1. Consultative process.

Therefore after each workshop, we produced a revised draft of the PTC. Figure 1 illustrates the consultative process.

The first drafts of the issues papers were discussed in a preconference workshop in conjunction with a Genomics, Ethics, Law and Society (GELS) satellite meeting in Quebec City. This workshop was attended by our collaborators and students.

These consultative workshops aimed to test our recommendations with other researchers, scholars and policy-makers who have an interest in social, ethical and legal issues related to public health genomics. Approximately 80 people attended the pre-conference consultative workshop at the time of the GELS satellite meeting in Calgary in April 2008. Participation was open to all conference registrants. Participants attending the Genome Can- ada meetings consist of experts in the ethical, legal, and social community of Canada as well as in the international community. A workshop was held with experts and collaborators in the spring of 2008. Finally, in February 2009, a workshop was held with federal policy-makers consisting of a group of 20 senior officials from the Public Health Agency of Canada, Health Canada, Justice Canada, Statistics Canada, Genome Canada, and the Canadian Institutes of Research to discuss the last draft of the PTC since after each workshop a revised document was circulated.

\section{Determination and Characteristics of State Powers}

In order to determine and characterise State powers, the evolution of both the concept and the core functions of public health were examined using a comparative approach (e.g. WHO, PAHO, CDC, and Quebec). Following the study of the Quebec legislation (Public Health Act [27]) and of the Act respecting Institut national de santé publique du Québec [28], the precautionary principle was then considered as a possible avenue to justify State access to and use of genomic databases for research purposes or in the case of a pandemic.

\section{Public Health and Its Essential Function}

First, it is crucial to realise that public health is a constantly evolving concept, focusing primarily on protection, but moving towards prevention and promotion. Moreover, the study of the essential functions of public health is helpful for the understanding of the legislation on public health, as well as its functioning and its scope of application. These functions are, as stated by the Pan American Health Organization, 'the fundamental set of actions that should be performed in order to achieve public health's central objective: improving the health of populations' [29].

An analysis of Quebec's Public Health Act reveals the nature and the scope of the powers attributed to the State in order to ensure its responsibilities regarding the protection of public health. The Act in its current formulation does not explicitly mention the possible creation of a data collection system of genomic information for research purposes under the ongoing health surveillance powers (sections $4,38,47$ ). However, in a public health emergency, the Government or the Health and Social Services Minister may have major powers; they may order, for example, 'any person, government department or body to communicate or give to the Government or the Minister immediate access to any document or information held, even personal or confidential information or a confidential document' and 'any other measure neces- 
sary to protect the health of the population' (section 123). Thus, in the event of the declaration of a public health emergency, access to and use of genomic information for the understanding of infectious and communicable diseases, as well as for disease prevention and health promotion, would be possible. It is important to realise that even if these emergency powers are broad, they are inappropriate in the research or health-promotion contexts. Because for such information to be useful in emergencies, it should already exist, implying that research has been undertaken. In other words, time is a limiting factor.

In 1998, Quebec's Institut National de Santé Publique (INSPQ) was established in order to contribute to the development, consolidation, dissemination, and application of knowledge in the field of public health and also to develop and promote research in the field of public health in collaboration with the various research organisations and funding bodies ('An Act respecting Institut national de santé publique du Québec', section 3). But can the INSPQ initiate genomic public health research by itself? It seems that this would be a challenge considering that the Government prioritises applied rather than fundamental research in the field of public health $[20,30]$. Genomic research is still considered as fundamental research.

Generally, the influenza pandemic plans consider genetics only under the guise of 'scientific information'. For example, the Canadian Plan [31] mentions the impact of 'information from the viral genome,' but no direct or indirect mention is made of genetic or genomic information as it relates to individuals, families or groups of citizens.

The necessity to obtain the best knowledge possible and to adopt the most effective measures is evident in the public health mandate. Therefore, can the collection and analysis of genetic or genomic information as a means of obtaining the best public health prevention and intervention strategies be carried out? Should such research be integrated in the essential functions of public health as a paramount activity, making it possible for the State to achieve the goals pursued? To answer these questions depends on the definition of public health research [20].

Recommendation: The definition of public health research should be: clear; oriented toward the health and the well-being of the population and its determinants; and not be limited to applied research but also embrace fundamental research while specifying a governance regime (e.g. authorization and oversight mechanisms as needed).

Public Health Genomics 2010;13:224-234
The Precautionary Principle: An Avenue to Explore

If the study of legislative texts does not allow us to conclude that at present, an explicit power exists to either create or to access and use genomic information for research purposes under the ongoing health surveillance power, is it then possible to invoke the precautionary principle to legitimise the State's power to intervene in this matter?

The 'Framework for the Application of Precaution in Science-based Decision Making about Risk' [32] outlines guiding principles for the application of precaution to science-based decision-making in the areas of federal regulatory activity regarding the protection of health, the environment and the conservation of natural resources. The concept of precaution is presented as resting on the notion that the absence of full scientific certainty should not be used as a reason for postponing decisions where there is a risk of serious or irreversible harm from not intervening. There are 3 fundamental components to the precautionary principle: the lack of full scientific certainty, the risk of serious or irreversible harm and the need for a decision [32].

Many interpretations that vary along the lines of the different aspects of the parameters of application (characteristics of measures adopted, precocity of its application, etc.) as well as the normative character of the concept of precaution have been devised, reviewed in the literature, and used in the public health context [33-35]. The 2 first versions, the institutional model and the cautious approach, can be qualified as antagonistic; correspondingly, they are based on the proportionality and the severity of precautionary measures adopted [17].

The institutional model, recognised by Justice Horace Krever's report in Canada's tainted blood scandal [36], aims to promote early action that is proportionate to the potential risks (e.g. heating blood products). The cautious approach encourages the implementation of more demanding precautionary measures and favours eradicating risks. It can be associated with the implementation of quarantine measures once fatalities occur (e.g. efforts to counter the presence of SARS [37]). In its most extreme form, it constitutes the rule of abstention or prohibition.

Two other versions of the precautionary principle also exist: the tactical approach and the strategic approach. They deal with the timeframe of the enactment of precautionary measures [17]. The tactical approach, often used in the area of food security, conceives precaution as a temporary and flexible instrument, where uncertainty can dissipate with the evolution of knowledge. It operates on the short and medium term. In this approach, measures 
are provisional and can be subject to change in response to increased knowledge (e.g. moratorium) [17]. The strategic approach relates to the 'Vorsorgeprinzip' developed in Germany which inspired the precautionary principle. The strategic approach is premised on the notion that obtaining scientific certainties cannot always be done in a timely manner so as to allow for the guidance of collective choices. Its proponents argue that a policy based on medium- and long-term objectives should be adopted. The implementation of surveillance systems and pre-authorised procedures illustrate the measures that correspond to this interpretation [17].

Recommendation: Among the different versions of the precautionary principle identified, the strategic approach could possibly establish the power for public health authorities to access and use genomic databases for research purposes and eventually utilize their findings in the context of public health interventions.

\section{Privacy}

The shift from genetic disease-oriented research to epidemiological genomic research involving large-scale sampling and the collection of personal data from different sources over time raises questions regarding privacy and confidentiality [21]. In this new context, personal data can be correlated from different sources (clinical and research records, administrative and public health databases, registries, genealogy, sociodemographics, economics, etc.) for population health research or public health planning. Association of large amounts of such data is necessary to attain statistical significance and measure gene-environment interaction. International collaboration involving transborder flow of data is a way to achieve such statistical power.

\section{From Genomics to Public Health (Federal, Quebec and Other Provinces)}

The logic of the actual legal framework (in Canada and countries under study) has its origins in the 1980 OECD Guidelines on the Protection of Privacy and Transborder Flows of Personal Data [38]. These fundamental guidelines fixed principles of access to personal data and have been integrated in legislation around the world. They indicate that the possible uses of personal data should be defined at the moment of the collection of data ('primary use') and should be limited to these purposes. Secondary uses must be in accordance with (a) the primary use agreed at the first consent or (b) the specific consent for the new purpose or (c) authorisation under law. These founding privacy guidelines inspired personal data legislation worldwide but did not address the secondary use of personal data for research purposes. More recently, OECD has proposed Guidelines for Human Biobanks and Genetic Research (2009) [39] and Principles for Access to Research Data from Public Funding (2007) [40], but neither address the question of access to personal data in a research context.

Population genomics research has the potential for a beneficial impact on public health. In fact, population genomics research infrastructures could be used for nested control studies, for replication, for validation, and generally as controls. They could also seemingly be used for ongoing public health surveillance.

Ongoing surveillance is usually the exclusive provincial function [e.g. the Minister of Health and Social Services in Quebec (Public Health Act)]. Within the scope of legitimate surveillance objectives, the Minister can require personal information from public or private bodies. All surveillance activity must be detailed in a surveillance plan reviewed by the Public Health Ethics Committee and authorised by the Access Commission.

Population genomics research in Quebec (as opposed to surveillance) is not governed by the Public Health Act and is therefore subject to the legislative and ethics norms governing biomedical research in general. Privacy laws of Quebec permit access to medical or personal information without consent for research purposes under certain conditions: (a) the necessity of identifiable information requested, (b) the assurance of confidentiality measures taken to protect that information and (c) the authorization of Quebec's Access Commission [41] (or the director of professional services [42] in health establishments). Ethics norms also require that authorisation from a research ethics board (REB) should be obtained before gaining access. Authorisations are given for a specific purpose (e.g. research project) and are limited in time. These conditions are not compatible with population genomics research, especially when involving databases and biobanks created for multiple future uses.

In the more recent laws of Alberta [43] and Ontario [44], 2 other criteria are used to qualify secondary uses of data without consent. First, the REBs must weigh the public interest in conducting the research and the public interest in protecting the privacy of the individuals whose personal health information is being disclosed. In the example of Alberta, the proposed research must outweigh 'to a substantial degree' the same public interest in preserving the privacy of personal information. The second- 
ary uses will therefore be allowed after need is balanced against privacy. Furthermore, the researcher will have to demonstrate that obtaining consent would be unreasonable, impractical, or not feasible. At the federal level in Canada, legislation governing the private sector has recognised the criterion of the impracticability of obtaining individual consent as an exemption [45].

Recommendation: Laws and research ethics guidelines should be reviewed and revised in accordance with the specificity of population genomics research. The aim is to ensure that the concepts of public interest as well as the definitions and conditions used in ethics review and in requests for access be clarified. The criterion of a reasonable possibility of identifiability of personal data based on the proportionality of risk rather than on the evaluation of all hypothetical risks may serve to resolve issues surrounding potential identifiability. The purpose of broad consent should be explained and accompanied by a high level of data security and governance. Secondary access to personal and health data for population-based research purposes should be considered as being in the public interest if the following conditions are met: (a) necessity: accessing such data is deemed necessary for research; (b) impracticability: re-contact for a new consent is impractical, unreasonable, or not feasible; (c) security: confidentiality and coding rules, appropriate technological and procedural mechanisms are in place for data security; (d) proportionality of risks: taking into account the reasonable risk of identifiability (as opposed to all hypothetical risks), the benefits of the research outweigh the privacy of personal information.

\section{Comparative Approaches to Access (Germany,}

Australia, United States and United Kingdom)

Genomic research often involves multiple jurisdictions and legislative compliance that may be difficult for researchers. An analysis of the approaches of these jurisdictions reveals an increasing recognition of the need to distinguish the individualistic consent and privacy ethics review norms of biomedical research from the population and epidemiological nature of genomics research that seeks to build infrastructures/resources for public health. Different tools for access exist or have been proposed in these countries based on the premise that scientific research is not an incompatible secondary use of personal health information. Approaches such as the 'research secret' in Germany, certificates of confidentiality in the United States, and the proportionality principle in the United Kingdom [46] have been proposed [21]. In Australia, the National Health and Medical Research Council adopted guidelines that stipulate that access is conditional on consent but that the latter could be waived by an ethics committee. For that, the Privacy Act proposes a public interest test that should guide a Human Research Ethics Committee [47].

Recommendation: Increasingly, genomic data are categorised as medical or personal information. Applying rules of confidentiality to researchers in the same manner as that of health care professionals (i.e. the obligation of medical secrecy) could add to the security of such data while safeguarding access.

\section{Stakeholder Perceptions}

While genomic research has the potential to generate knowledge applicable to public health, access to genomic databases and the relevance of such to public health research raises ethical questions among stakeholders [48]. Stakeholders can be defined as any party to a transaction which has particular interests in the outcome or alternatively who may win or lose by a particular policy [49], or as those who will be affected by a project, or who can influence it [50]. In our analysis, a high value was placed on the views of stakeholders in the process of garnering the resources necessary for public health genomics research and in introducing communication mechanisms and appropriate ethical frameworks. In order to understand and elucidate the perceptions of stakeholders as to the relevance of genomic research for public health and related issues, in-depth interviews were conducted with policymakers, epidemiologists, virologists, genomics researchers, and ethics and law specialists concerned with public health genomics issues [22].

The different concerns of the stakeholders were ranked according to their importance. The qualitative analysis identified the following key elements: biobanking, governance, public health powers of surveillance, and mechanisms to protect the public when considering research in public health genomics.

\section{Biobanking - a Public Good}

Public health research is often presented as a public 'good' and population genomics databases are presented as being 'public goods.' What does this mean for the various stakeholders involved? There was a consensus to the effect that the use of genomic data must serve the interests of the population. Concerning the possibility of linking data from genomic research with governmental databases, public health professionals, and genomic researchers saw immense research potential but considered that 
appropriate steps needed to be taken to safeguard access to the data. The relevance of combining national and international data and their value for research was also recognised [22].

Recommendation: Genomic biobanks should be in the public interest and financed by public funds. To that end, a framework is needed to weigh data access and its value for research. Furthermore, the possibility of combining national and international data as well as linking data from genomics and governmental databases should be examined.

\section{Governance}

In order to protect research participants, authorization by a REB should be obtained for all research carried out using population genomic databanks. Consent from participants, confidentiality (by removing identifiers from the data), safeguarding access to the data, and governance were considered essential. However, there are exemptions to consent regarding access to data both for research and as part of the surveillance powers of public health just as there are constraints on public health in exceptional circumstances.

Although the consent of participants is in general necessary in research, there is currently an ambiguity, or a debate, regarding what constitutes research in public health and what constitutes surveillance. From a genomics and public health research perspective, peer-review and that of ethics committees are a means to ensure the protection of participants. However, the need remains for follow-up on the actual handling of data so as to determine whether approved research projects are properly carried out.

The process of consent remains unquestionable so as to ensure the respect and protection of research participants. Some stakeholders recognised the advantage of relaxing consent constraints on genomic population research, but they did not advocate diminished responsibilities for researchers. Reflecting this new vision, the consent would need to be explicit that future uses of the data remain unknown, but that its security will be ensured, thus allowing for greater openness to secondary uses through a broad consent procedure. Furthermore, the consent should clarify which governmental databases will be accessed. A certain degree of openness to consent is favoured, but not to the extent that it becomes a 'carte blanche' [22].

Recommendation: Biobanks should have a governance structure. The integration of genomics into public health research necessarily requires: (a) an ethical evaluation by a research ethics board; (b) confidentiality, coding of data and mechanisms for protecting access to data; (c) although exemptions for consent to access data are already part of the surveillance powers of public health authorities, consent for research using population genomic databases should be a requirement; but (d) a broad consent allowing secondary uses for research using population genomic databanks should be permitted.

\section{Public Health Powers of Surveillance}

Public health strategies could include the surveillance of genetic resistance or susceptibility (i.e. identification of relevant and useful information about public health in terms of the state of health of the population) or to improve understanding prior to an intervention. Despite this fact, no stakeholder noted the possibility that public health initiatives could require access to population genomic databanks for research purposes as well. The immediate utility or possibility of the application of genomic research in public health for epidemics was not considered because according to them, current scientific evidence does not yet justify it [22].

Recommendation: Although public health strategies could lead to the surveillance of genetic susceptibility, a genetic susceptibility screening program should never be mandatory. The relevance of integrating genomics into public health research should be assessed. Such integration should be made by a multidisciplinary team with the involvement of citizens. Solid scientific evidence and indicators of health determinants for public health genomics research should be evaluated and justified.

\section{Mechanisms}

Different actions are possible when considering research in public health genomics. The following points need to be addressed: (1) the elaboration of mechanisms to protect research participants in population genomics; (2) the dissemination of information in a clear and transparent way regarding future research plans, the research results, and possible interventions based on this genomic data; (3) the carrying out of well-designed research projects in order to generate solid evidence on which to base the development of new interventions; (4) the education of health professionals and decision-makers about genomics; and (5) the harmonisation or standardisation of the ethical framework of research in genomics [22]. It is also crucial to create a decision-making framework and to evaluate the relevance of the integration of genomic tools into the public health agenda.

Recommendation: Transparent and balanced communication should be provided as well as accountability pro- 
cedures so as to foster acceptability of population genomics research, protection of research participants, involvement of decision-makers, and engagement of scientists in 'sound science'. To that end, the education of stakeholders, including citizens, about genomics should be strengthened.

\section{Public Participation}

In response to the challenges that the different forms of the influenza virus generate for public health authorities around the world, many member States (e.g. Brazil, United Kingdom, Switzerland, Canada, and New Zealand) of the WHO have developed a number of measures aimed at preventing and combating a possible pandemic [23]. These measures are outlined in national plans produced by agencies or ministries in charge of the protection of the public should a pandemic occur. Given the magnitude of the powers and responsibilities assumed by the State when pandemics occur, an analysis of the various national pandemic influenza preparedness and response plans points to a number of significant ethical concerns: the role of genomics in pandemic plans, the presence of ethical frameworks, and citizen participation, with a view to their possible use for understanding the possible relation between genomic susceptibility and public health.

\section{Role of Genomics in Pandemic Plans}

Due to the scientific advances made possible by research undertaken in the Human Genome Project, there is increasing focus on the possibility of using genomic tools to resolve a number of public health problems. An example of this is the SARS epidemic, with some experts suggesting that genomic information could effectively help to combat the epidemic [51]. In this vein, the use of genetic information is sanctioned for the building of biobanks and databases, which make possible the establishment of certain correlations between genetic variations observed within a population and the susceptibility to certain illnesses. The role of genomics in each of the national pandemic plans was examined in order to understand whether the use of genetic information could modify certain ethical concerns (e.g. confidentiality, consent, etc.) or have an impact on public perception. Perusal of the plans found scant reference to genomics. Only the Swiss plan and that of the United Kingdom mention a possible use of genetic techniques for characterizing the virus [23].

Most of the plans analysed put the emphasis on the necessity of creating and maintaining public confidence, first by the transparency of the decision-making, and second by the accessibility, timeliness, and relevance of the information. Generally, the plans envisaged only 'unidirectional' communication (e.g. survey polls) in which the citizen is perceived above all as having a subordinate role, or simply as a carrier of the illness to be 'controlled' so as to reduce the risks of a pandemic. There are only 2 plans that constitute exceptions to this approach, those of Brazil and the United Kingdom. These plans include consultations with the lay public [23].

Recommendation: Given the foreseeable and increasing use of genomic information in response to public health emergencies such as pandemics and its potential impact on important ethical issues, the role of genomics should be explicitly developed within pandemic plans.

\section{Ethical Frameworks}

In spite of the obvious importance of ethical questions associated with issues such as the distribution of resources (e.g. vaccines), or with measures of surveillance or control that could result in restrictions on individual freedom, the majority of the plans by member States of the WHO did not contain an ethical framework. Neither was there mention of the ethical principles involved in the decision-making process regarding the stockpiling of vaccines and antivirals.

Three plans constitute an exception to this rule: Canada, New Zealand, and Switzerland [23]. The Canadian plan prioritises the principles guiding the implementation of interventions should there be a pandemic. This framework seeks to balance the ethical principles related to public health with the principles of clinical ethics applicable in the same situations. The Swiss plan also sets forth certain overriding principles to guide public health authorities. However, it is more focused on the allocation of vaccines when resources are rationed. The New Zealand ethical framework simply lists the values to be considered in the decision-making process and content in the event of a pandemic.

Recommendation: Given the sensitivity of many ethical questions related to public health response and preparedness to pandemic influenza, all national plans should include substantial and well-designed ethical frameworks guiding the decision-making process.

\section{Citizen Participation}

To the extent that citizen participation is considered to be essential to the success of these plans, and in view of the restrictions which the population could endure in the event of a pandemic emergency, public participation is 
fundamental [52]. This is an ethical issue to which the experts, charged with developing and administering the plans, must devote themselves. Effective public health strategies must be able to rely on well-founded data on the frequency, distribution, determinants, and consequences of illnesses, while at the same time carefully evaluating the level of effectiveness and the security of proposed interventions. To reach this goal of developing, managing and using exact scientific knowledge in public health, 'lay' knowledge is too often neglected and underestimated [23].

In order to start a public dialogue on public health issues, the Groupe de recherche en Bioéthique of l'Université de Montréal held a citizen workshop in April 2008 to discuss the possible role of citizens in the development of pandemic influenza plans [24]. The final outcome of this workshop confirmed several of the Group's initial hypotheses. For instance, citizens have a basic understanding that can complement expert knowledge in the decision-making process. The citizens who participated in the workshop also affirmed the importance of solidarity and that all members of society must assume individual responsibility during a pandemic situation and that there is an increasing need to develop civic security [24].

In brief, citizen perspectives should be actively sought and integrated into governance and ethical frameworks. When seeking such perspectives, bidirectional approaches, i.e. a process in which citizens, experts and decision-makers create and share information to reach a mutual understanding [53], such as in citizen conferences [25], should be preferred to unidirectional approaches where experts or decision-makers transmit their knowledge to the general public. A diversity of points of view can be ensured by involving a broad range of publics (general public, decision-makers and experts). A transparent, balanced communication strategy is essential for accountability. This will foster the acceptability of population genomic research, protect research participants, involve decision-makers, and engage scientists in 'good science' [52]. To that end, the education of citizens, experts, and decision-makers about genomics should be strengthened.

Recommendation: Given its general contribution to a more effective management of public health emergencies, all national plans should include a 'bidirectional' approach through mechanisms of consultation and participation of the general public.

\section{Conclusion}

The partition between public health practice, genomic research, and policy need not to continue. Health, including public health research, is today accepted as an important policy area. 'This change is influenced by growing health threats such as communicable diseases [...]' [54]. But, the delivery of population genomic research and medicine, even for chronic diseases, is still in its early stages. '[T] he gaps to be filled to bring genomic medicine to fruition are exceedingly complex' [55] and public health strategies lack the translational tools [56] for an integrated approach. The policy tools required to meet these challenges may benefit from consideration of the points raised by our research.

While this paper has used infections and communicable diseases as a case study for the use of population genomic research, it will hopefully have provided a more coherent response not only to the framing of possible uses of genomic databases for research and health planning in those fields, but also to the translation of genomic knowledge into awareness for disease prevention and health promotion generally.

\section{Acknowledgments}

The authors appreciate the contributions of our international advisory committee and our collaborators as well as study participants, experts, and students. We appreciate the financial support of Genome Quebec and Genome Canada via the grant 'Genomics and Public Health: Building Public "Goods"?' The authors acknowledge the contribution of Ma'n H. Abdul-Rahman, Professional Associate, to the final draft of this article.

References

1 Omenn GS: Special challenges in applying genomics to population health. J Biolaw Bus 2001;4:3-6.

$\checkmark 2$ Knoppers BM, Brand AM: From community genetics to public health genomics - what's in a name? Public Health Genomics 2008; 12 : $1-3$.

-3 Khoury MJ, Thrasher JF, Burke W, Gettig EA, Fridinger F, Jackson R: Challenges in communicating genetics: a public health approach. Genet Med 2000;2:198-202.

-4 Beskow LM, Khoury MJ, Timothy G, Baker TG, Thrasher JF: The integration of genomics into public health research, policy and practice in the United States. Community Genet 2001;4:2-11.

5 Collins FS: The case for a human genome epidemiology initiative. Nature 2004;429:475477. 
6 Taylor HA, Johnson S: Ethics of population based research. J Law Med Ethics 2007;35: 295-299.

-7 Brand A, Brand H, Schulte in den Bäumen T: The impact of genetics and genomics on public health. Eur J Hum Genet 2008;16:5-13.

8 Brand AM, Probst-Hensch NM: Biobanking for epidemiological research and public health. Pathobiology 2007;74:227-238.

-9 Guinn M, Khoury MJ: Research priorities for public health sciences in the post-genomic era. Genet Med 2002;4:410-411.

$\checkmark 10$ Verity C, Nicoll A: Consent, confidentiality and the threat to public health sciences in the postgenomic era. BMJ 2002;324:1210-1213.

11 Lin Z, Owen AB, Altman RB: Strategies for protecting privacy in the genomic era. Genet Eng News 2004;24:8.

12 Kosseim P, Brady M: Policy by procrastination: secondary use of electronic health records for health research purposes. McGill J Law Health 2008;2:5-45.

13 Fonds de Recherche en Santé du Québec (FRSQ): Final report, advisory group on a governance framework for data banks and biobanks used for health research, 2006;82. Available at http://www.frsq.gouv.qc.ca/en/ pop_accueil/quoi_neuf.shtml.

14 Knoppers BM: Of genomics and public health: building public 'goods'. CMAJ 2005; 173:1185-1186.

15 Mladovsky P, Mossialos E, McKee M: Improving access to research data in Europe. BMJ 2008;336:287-288.

16 Academy of Medical Sciences, Personal Data for Public Good: Using health information for medical research. United Kingdom, 2006. Available at www.acmedsci.ac.uk.

17 Godard O: Le principe de précaution comme norme de l'action publique, ou la proportionnalité en question. Revue économique 2003;54:1245-1276.

18 Knoppers BM (ed): Genomics and Public Health: Legal and Socio-Ethical Perspectives. Leiden, Martinus Nijhoff, 2007.

19 Research Group in Bioethics at the University of Montreal, 4th International DNA Sampling Conference: The efficiency and efficacy of citizen participation models in the elaboration of public policy. OMNI Hotel, Montreal, June 4-7, 2006.

20 Cousineau J: Pouvoirs de l'État en matière de santé publique et essor de la recherche en génomique: deux réalités convergentes au Québec? Lex Electronica 2008; 13:1-9.

21 Fortin S, Knoppers BM: Secondary uses of personal data for population research. Genomics Soc Policy 2009;5:80-99.

22 Godard B, Lévesque L: Genomics and public health: building public 'goods' stakeholders 'point of view'. Public Health Genomics 2010 , in preparation.

23 Farmer Y, Bouthillier ME, Dion-Labrie M, Durand C, Doucet H: Public participation in national preparedness and response plans for pandemic influenza: toward an affirmation of the ethics of public health policies. Public Health Ethics J 2009, in preparation.
24 Groupe de Recherche en Bioéthique de l'Université de Montréal: Rapport: atelier de dialogue citoyen sur la contribution des citoyens à l'élaboration des plans de lutte contre la pandémie d'influenza. GREB, Université de Montréal, 2009.

25 Dion-Labrie M, Durand C, Farmer Y, Bouthiller ME, Doucet H: Guide for planning, conducting, and assessing a citizens' conference. GREB, Université de Montréal, 2009.

26 Farmer, Y, Durand C, Dion-Labrie M, Bouthillier ME, Doucet H: Quelle peut être la contribution des citoyens à l'élaboration des plans deluttecontrelapandémied'influenza? Échos d'une expérience québécoise sur la participation citoyenne. Éducation santé, No 243, 2009.

27 Regulation under the Public Health Act: R.S.Q., c. S-2.2.

28 An Act respecting Institut national de santé publique du Québec. R.S.Q. c. I-13.1.1.

29 Pan American Health Organization: What are the EPHF? Available at http://www.paho. org/English/DPM/SHD/HP/EPHF.htm.

30 Gouvernement du Québec - Ministère de la santé et des services sociaux - Direction générale de la santé publique. Québec National Public Health Program 2003-2012 (2003). Available at www.rrsss12.gouv.qc.ca/documents/Programme_nationale_sante_pub. pdf.

31 Her Majesty the Queen in Right of Canada, Canadian Pandemic Influenza Plan for the Health Sector (2006). Available at www. phac-aspc.gc.ca/cpip-pclcpi/pdf-e/CPIP2006_e.pdf.

32 Government of Canada: The Framework for the Application of Precaution in Sciencebased Decision Making about Risk (2003). Available at http://www.bcp-pco.gc.ca/docs/ information/publications/precaution/ precaution_e.pdf.

33 Noiville C, Gouyon PH: Principe de précaution et organismes génétiquement modifiés; in Kourilsky P, Viney G (eds): Le Principe de Précaution. Paris, Éditions Odile Jacob, 2000.

34 Dormont D, Hermitte MA: Propositions pour le principe de précaution à lumière de l'affaire de la vache folle; in Kourilsky P, Viney G (eds): Le Principe de Précaution. Paris, Éditions Odile Jacob, 2000.

35 Setbon M: Le cas du sang contaminé confronté au principe de précaution; in Kourilsky P, Viney G (eds): Le Principe de Précaution. Paris, Éditions Odile Jacob, 2000.

36 Commission of Inquiry on the Blood System in Canada (Krever Commission): Krever Commission Report. Ottawa, Public Works and Government Services Canada, 1997. Available at http://epe.lac-bac.gc.ca/100/ 200/301/hcan-scan/commission_blood_ final_rep-e/index.html.

37 Campbell Commission, The SARS Commission - Spring of Fear: Final report. Toronto, Government of Ontario, 2006. Available at http://www.health.gov.on.ca/english/public/pub/ministry_reports/campbello6/online_rep/index.html.
38 Organization for Economic Co-operation and Development (OECD): Guidelines on the Protection of Privacy \& Transborder Flows of Personal Data. Paris, 1980.

39 Organization for Economic Co-operation and Development (OECD): Guidelines for Human Biobanks and Genetic Research Databases. Paris, 2009.

40 Organization for Economic Co-operation and Development (OECD): Principles for Access to Research Data from Public Funding. Paris, 2007.

41 An Act Respecting Health Services and Social Services. R.S.Q., c.S-4.2, s.19.2.

42 An Act Respecting Access to Documents Held by Public Bodies and the Protection of Personal Information. R.S.Q., c.A-2.1, s.59 and s.125.

43 Health Information Act. R.S.A, 2000, c.H-5, s.50 (1) (b).

44 Personal Health Information Protection Act, S.O. 2004, c.3 ann. A, s.44(3).

45 Personal Information Protection and Electronic Documents Act, 2000, c.5, s.7(2)(c).

46 Article 29, Data Protection Working Party, Opinion 4/2007 on the concept of personal data (2007). Available at Justice and Home Affairs: Freedom, Security and Justice. http://ec.europa.eu/justice_home/fsj/privacy/docs/wpdocs/2007/wp136_en.pdf.

47 Commonwealth Privacy Act: 1988, No. 119. Available at http://www.comlaw.gov.au/ ComLaw/Legislation/ActCompilation1.nsf/ framelodgmentattachments/409069FCABD 20271CA25725C008385B5.

48 Farmer Y, Godard B: Public Health Genomics (PHG). From scientific considerations to ethical integration. Genomics Soc Policy 2007;3:14-27.

49 World Health Organization: The World Health Report 2000. Health systems: improving performance. 2000.

50 Freeman ER: Strategic Management: A Stakeholder Approach. Boston, Pitman, 1984.

51 Larkin M: Technology confronts SARS. Lancet Infect Dis 2003;3:453.

52 Avard D, Grégoire G, Jean MS: Involving the public in public health genomics: a review of guidelines and policy statements. GenEdit 2008;6:1-9. Available at http://www.humgen.umontreal.ca/int/GE/en/2008-1.pdf.

53 Fawkes J: Public relations and communications; in Theaker A (ed): The Public Relations Handbook. London, Routledge, 2001, pp 13-23.

54 Stein $\mathrm{H}$ : Supporting and using policy-oriented public health research at the European level. Public Health Perspect 2008;14:19.

55 Ginsburg GS: Genomic medicine: 'grand challenges' in the translation of genomics to human health. Eur J Hum Genet 2008; 16: 873-874.

56 Burke W, Khoury M, Stewart A, Zimmern R, the Bellagio Group: The path from genomebased research to population health: development of an international public health genomics network. Genetics and Medicine 2007;8:451-458. 